\section{Enhanced Healing of Sacral and Pubic Insufficiency Fractures by Teriparatide}

\section{To the Editor:}

We describe healing of enhanced insufficiency fracture of combined pubic rami and sacrum by daily teriparatide (1-34 PTH) injection.

A 73-year-old woman was admitted because of acute low back and groin pain. She denied any trauma history. Plain radiographs revealed fracture of the left superior ramus (Figure 1A). Because of the disproportionate pain and lack of response to analgesics with bed rest for 2 weeks, a bone scan was arranged and showed sacral and 4 rami fractures (Figure 1B). Daily teriparatide injection was initiated with calcium $1000 \mathrm{mg} /$ day and vitamin D 400 IU/day supplements for osteoporosis. At 3 months' fol- lowup, the pain had subsided completely, with abundant callus formation on rami fractures (Figure 1C). The fractures showed good consolidation at the end of 18 months (Figure 1D).

Sacral combined with rami insufficiency fractures usually occur in osteoporotic bone and are often underdiagnosed ${ }^{1}$. Management includes bed rest, analgesic, and gradual mobilization ${ }^{2}$. Owing to its relationship to osteoporosis, additional medications for enhancing bone strength and preventing further fractures are mandatory.

There are many reports about the fracture-healing potential of teriparatide and its analog for femoral neck ${ }^{3}$ and pubic insufficiency fractures ${ }^{4}$. Our experience may expand the applications of anabolic agents for osteoporosis.
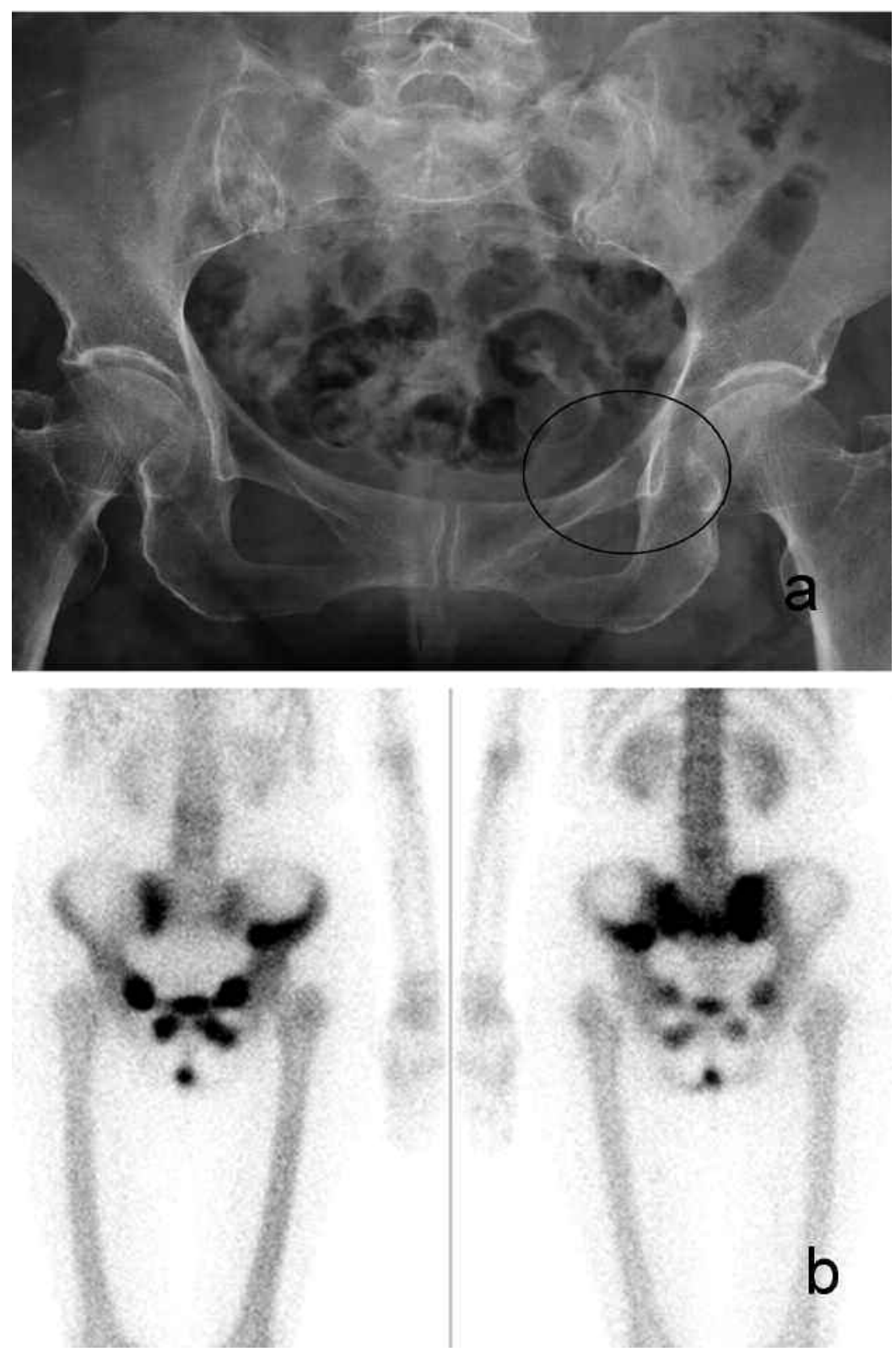

Figure 1. A. Plain radiograph reveals left superior ramus fracture (circle). No fracture noted on other 3 rami. B. Bone scan demonstrates increased uptake of 4 rami and sacrum (" $\mathrm{H}$ sign), consistent with insufficiency fractures. 

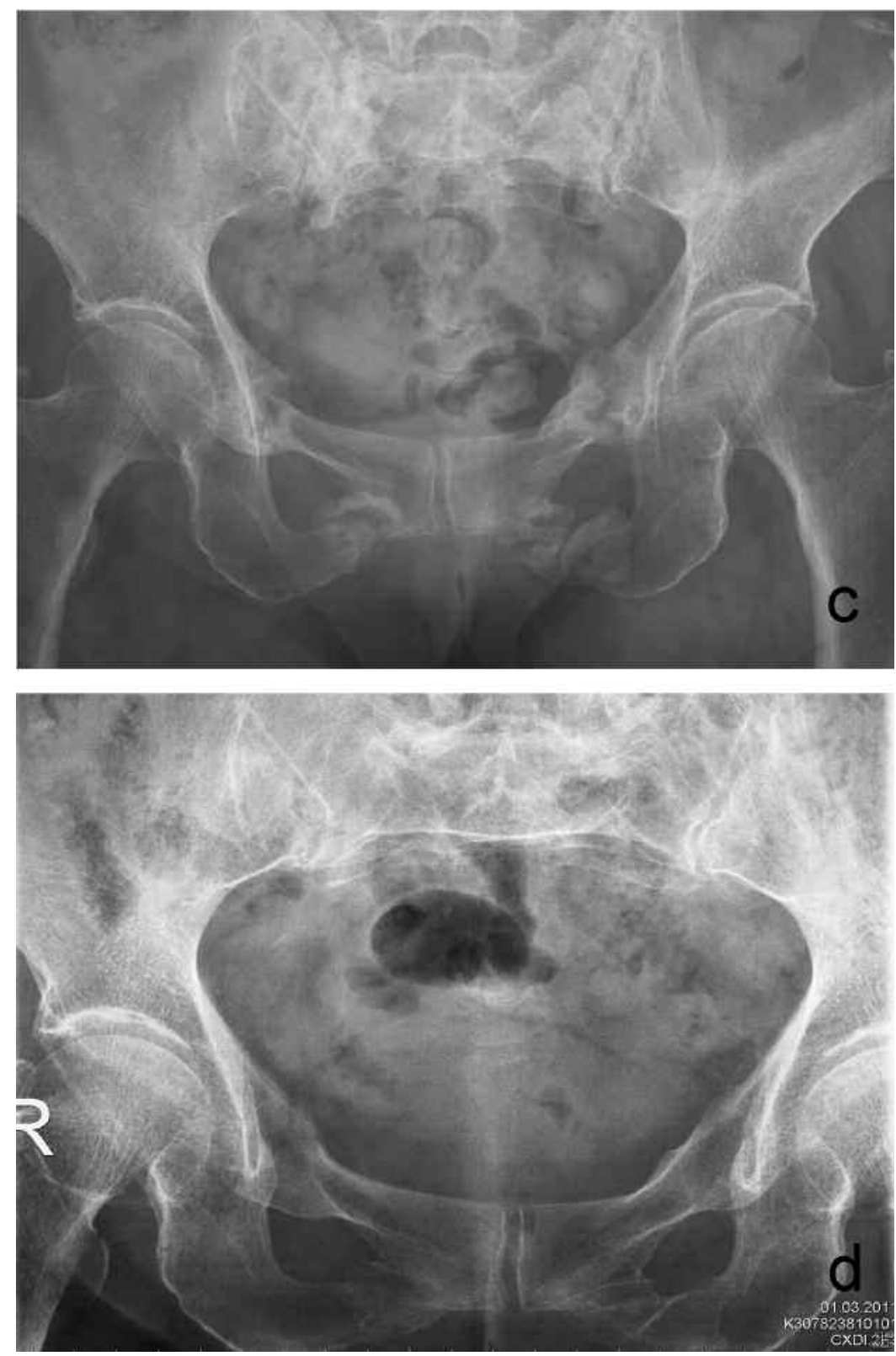

Figure 1.C. Abundant callus formation after teriparatide for 3 months. D. Complete union and remodeling of pubic rami fractures at 18 months' followup.

CHIA-CHIEH WU, MD, Department of Orthopedic Surgery, Changhua Christian Hospital, Changhua, Taiwan; JAMES CHENG-CHUNG WEI, MD, PhD, Division of Allergy, Immunology and Rheumatology, Institute of Medicine Chung Shan Medical University Hospital, Taichung, Taiwan; CHEN-PU HSIEH, MD; CHEN-TUNG YU, MD, MSc, Chief, Section of Bone Disease, Department of Orthopedic Surgery, Changhua Christian Hospital.

Dr. Yu is a speaker for Eli Lilly and Co., MSD, Novartis, and Roche. Address correspondence to Dr. C-T. Yu, Section of Bone Disease, Department of Orthopedic Surgery, Changhua Christian Hospital, 135 Nan-shiao Street, Changhua City 500, Taiwan.

E-mail: ortho.yu@msa.hinet.net

\section{REFERENCES}

1. Lourie H. Spontaneous osteoporotic fracture of the sacrum: An unrecognized syndrome of the elderly. JAMA 1982;248:715-7.

2. Tsiridis E, Upadhyay N, Giannoudis PV. Sacral insufficiency fractures: Current concepts of management. Osteoporosis Int 2006;17:1716-25.

3. Yu CT, Wu JK, Chang CC, Chen CL, Wei JC. Early callus formation in human hip fracture treated with internal fixation and teriparatide. J Rheumatol 2008;35:2082-3.

4. Peichl P, Holzer LA, Maier R, Holzer G. Parathyroid hormone 1-84 accelerates fracture-healing in pubic bones of elderly osteoporotic women. J Bone Joint Surg Am 2011;93:1583-7.

J Rheumatol 2012;39;6; doi:10.3899/jrheum.111458 